Georgetown University Law Center

Scholarship @ GEORGETOWN LAW

1987

\title{
Causation in Torts, Crimes, and Moral Philosophy: A Reply to Professor Thomson
}

Paul F. Rothstein

Georgetown University Law Center, rothstei@law.georgetown.edu

This paper can be downloaded free of charge from:

https://scholarship.law.georgetown.edu/facpub/399

76 Geo. L.J. 151-167 (1987)

This open-access article is brought to you by the Georgetown Law Library. Posted with permission of the author. Follow this and additional works at: https://scholarship.law.georgetown.edu/facpub

Part of the Law and Society Commons, and the Torts Commons 


\title{
GEORGETOWN LAW Faculty Publications
}

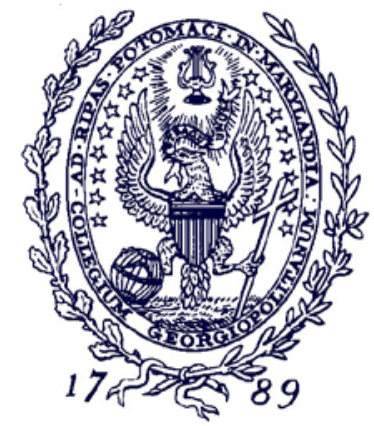 \\ July 2008

\section{Causation in Torts, Crimes, and Moral Philosophy: A Reply to Professor Thomson}

76 Geo. L.J. 151-167 (1987)

Paul Rothstein

Professor of Law

Georgetown University Law Center

rothstei@law.georgetown.edu

This paper can be downloaded without charge from:

Scholarly Commons: http://scholarship.law.georgetown.edu/facpub/399/

SSRN: $\underline{\text { http: } / / \text { ssrn.com/abstract }=1154196}$

Posted with permission of the author 


\title{
Causation in Torts, Crimes, and Moral Philosophy: A Reply to Professor Thomson
}

\author{
PAUL F. RothSTEIN*
}

Professor Judith Jarvis Thomson's provocative article, "The Decline of Cause," 1 focuses on the diminishing importance of causation in law and moral philosophy. In this reply, I suggest answers to some of the questions Professor Thomson raises.

Professor Thomson's article revolves around various forms of a classic dilemma: two persons take equal care but, through chance, their actions produce different results. Does the outcome of their actions matter in a moral assessment of those actions? Professor Thomson first sets out what she styles as the Kantian and "moral sophisticates" " position that the outcome of an act does not and should not affect our assessment of the moral quality of the act. Subsequently, however, Thomson rejects the absolute nature of this position. She concludes that, in cases of acts blameworthy in the first instance-i.e., blameworthy on some ground independent of the actual outcome-resulting harm or near harm does and should render our moral assessment more negative than it would be absent such result. Professor Thomson confesses herself to be largely at a loss to explain why we hold these moral intuitions, and thus she does little more than posit-rather than explain - them. ${ }^{2}$

In the first part of my reply to Professor Thomson, I explain why the reasoning that leads her to reject the Kantian position is flawed-why, in fact, her own arguments lead to the conclusion that the Kantian position is correct and that outcome does not matter in our moral assessment of a person's acts. In the second part of my reply, I accept for the sake of argument Professor Thomson's position on Kant and the "moral sophisticates," and I address her ultimate intuitive conclusion that outcome does matter, but only in cases of fault in the first instance. I submit that I can offer Professor Thomson reasons for her intuited conclusion, reasons which explain not only

\footnotetext{
* Professor of Law, Georgetown University Law Center.

1. 76 GEO. L. J. 137 (1987).

2. Professor Thomson, I believe, has been misled by something the law does for purely practical or administrative reasons and not moral reasons. The tort law "punishes" careless (or even intentional) conduct only when harm results from it. The criminal law often (but not invariably) does the same. The law does not draw the same distinction for acts that are determined not to be careless or wrongful-they go unpunished whether harm results or not. (But strict liability and no-fault auto liability are counter to this and eventually may also influence moral perceptions. Similarly, ancient trespass law "punished" even "non-wrongful" acts that resulted in harm.) Professor Thomson concludes from this general thrust of the law that results matter morally only when the conduct was wrongful in the first place.
} 
why outcome matters in cases of fault in the first instance, but why it matters in all cases-including cases of no fault in the first instance.

\section{Kant AND THE Moral Sophisticates}

I believe that moral judgments should turn on a person's acts, not on their results. In addition, it seems to me that most people, when they rigorously examine their moral judgments, view matters in this way. Despite her stated conclusion, even Professor Thomson's own arguments lead to this conclusion.

For example, at one point in her paper Professor Thomson introduces a distinction between act and person. She presents us with two hypothetical drivers who, in backing down their driveway, are equally at fault in the first instance, i.e., careless. Through sheer chance, one hits a child, while no child is in the way of the other. Thomson admits that the driver with the "bad luck" to have a child in the way is morally no worse a person than the one who was "lucky" enough not to have a child in the way. She insists, however, that the act of the one is worse than the act of the other. ${ }^{3}$ Moral judgment of a person, she says, must be passed on the basis not only of what was true about the circumstances surrounding that person's acts but also on the basis of what the person would do if certain "counter-factuals" were true. That is, the judgment must be based on the harm the driver who had no child in the way would have inflicted if there had been a child in the way, or even how often a person who never drives would carelessly back out of his driveway if he did drive.

This comes to nothing more than saying that a person is to be judged based on what he does, or would do, irrespective of the outcome. And Thomson is indeed correct: this is the proper set of criteria on which to render a moral judgment of a person. But a person's acts are merely part of these criteria, not somehow separate moral entities which are morally measurable independent of the person who commits them.

Nevertheless, Thomson points out that in the one case and not the other a

3. Kant and the moral sophisticates believe that the crucial factor for moral judgments is intention, i.e., the "setting of oneself." In a sense, "acts" are consequences of intentions. Thus, by separating off "acts" from "persons," and judging the moral quality of acts separately, Prof. Thomson builds in the answer she wants: that consequences matter. (This may even go a bit further than she wants: it means consequences matter as to acts that are not blameworthy in the first instance, as well as those that are blameworthy.) Prof. Thomson's terminology, throughout most of the paper, itself largely ignores any distinction between act and person, speaking interchangeably of the two. The distinction seems to appear as a way to minimize the damage from the fact that moral judgments do seem independent of result in many cases where such would not be allowed by the main theory.

I do not want to suggest that the distinction between act and person has no utility in any context. The law of entrapment, with its concept of predisposition, makes some use of the distinction, at least theoretically. 
child is killed. She admits that this is due solely to chance, but asserts that, somehow, the difference is a moral one, and "of a very grave order. For the one [driver] is by his negligence to blame for a death, and the other is not."4 This does not state a reason why the difference is morally significant; it simply asserts that it is. In fact, by saying that one of the drivers is "to blame" for a death, Professor Thomson is merely using the phrase "to blame" to mean "caused" and exploiting the not infrequent use of "to blame" as a term connoting increased moral disapprobation. Conversely, when Professor Thomson says the careless driver who fortuitously had no child in his path is "not to blame" for a death, all this means is that a blameworthy act did not, by chance, cause or produce a death as its consequence. ${ }^{5}$ It is also interesting to note that even though we would not say he is "to blame for a death," we would still say he is "to blame," or even "to blame for creating a hazard," and there is nothing in Professor Thomson's essay that demonstrates such blame is any less than if a death were caused.

Professor Thomson fosters the illusion that outcome matters in cases of fault in the first instance by means of a brief analysis of the role of luck in morality. She states that a truck driver who is not at fault in the first instance in maintaining his brakes, yet who hits a child-“"Unlucky No Fault Driver," in Professor Thomson's terminology-is unlucky in two ways: first, that there is a child present, and second, that he is unable to stop. By contrast, a truck driver who is at fault in the first instance because he negligently maintains his brakes, and who also hits a child-“Unlucky Fault Driver"-is unlucky only in that there is a child present; his inability to stop is due to his own negligence.

Professor Thomson posits that because bad luck appears as both ingredients in the case of the Unlucky No Fault Driver, and as only one ingredient in the case of the Unlucky Fault Driver, luck is entirely to blame for the first death but not the second. Since two bad lucks is morally better than one bad luck plus bad conduct, she concludes that the first case is morally better than the second. This, to me, "smells too much of the study,"6 and not enough of reality, to use a phrase Professor Thomson uses against her own critics.

But more important, it compares the wrong cases. No one would dispute that a negligent in the first instance driver who hits a child is worse than a non-negligent in the first instance driver who also hits a child. If the issue is

4. Thomson, supra note 1 , at 146 (emphasis in original).

5. Furthermore, by accepting on the above grounds the proposition that the consequences of an act add some increment of moral fault to acts involving fault in the first instance, Professor Thomson finds herself at a total loss to explain why nearly missing a child adds a similar increment of blame. (Possible explanations based on risk would be unsatisfactory to her for a number of reasons, and would undermine her whole theory.) This is a flaw from which my view of the use of an act's consequences does not suffer.

6. Thomson, supra note 1 , at 143. 
the moral effects of different results on otherwise identical cases, however, the at fault in the first instance driver who hits a child must be compared not with his no fault in the first instance counterpart, but rather with the fault in the first instance driver who does not hit a child because none is present"Lucky Fault Driver." (Similarly, the no fault in the first instance driver who hits a child must be compared with the no fault in the first instance driver who does not.) ${ }^{7}$ Professor Thomson says that "it remains a counterfactual truth about [Lucky Fault Driver] that if he had [had the bad luck to have a child present], then he too would have been unable to stop his truck in time." As mentioned above, Professor Thomson states that such counterfactual truths must be taken into account in our moral judgments of persons; if we are correct in deciding that acts cannot be judged independently of persons, then Lucky Fault Driver and Unlucky Fault Driver must deserve identical moral culpability for their actions, regardless of the different results they produce.

The moral sophisticates hold that the bad outcome adds no increment of fault in the case of the "fault" driver. Professor Thomson states, at this point in her paper, that what they are saying is "a man cannot be thought to blame for something if bad luck entered in any way at all into the history of his bringing it about. But that seems to me even on its face implausible." She proceeds to illustrate the absurdity of the proposition by creating a hypothetical defendant who attempts to murder a man who, unbeknownst to him, usually wears a bullet proof vest; the murder attempt succeeds because the

7. At another point in her paper Prof. Thomson states that these two are equally without fault (in accord with her general proposition that morally we make a distinction based on result only in cases of fault in the first instance). To me, this is counterintuitive. Of these two supposedly "nofault" drivers, the one who hits a child will even himself feel that he is more blameworthy than the one who doesn't; i.e., that perhaps he hadn't been as careful as he should or as the other was. The next section of the article shows why I think this is entirely appropriate. Professor Thomson makes the mistake of thinking that because neither of these two drivers rises to the level of serious or legal fault, they are both equally without any fault. In support, she shifts the meaning of the word "blame." She says we would say the "no-fault" driver who hits a child is not "to blame" for the child's death (and thus is equivalent to the "no-fault" driver who hits no child). But, using "blame" in the sense of meaning "cause," we often would say the "no-fault" driver who hits a child is "to blame" for the death-especially when trying to describe a way he is different from a driver ("fault" or "no-fault") who caused no death. We may mean more than merely "caused" by this. (Indeed, ancient trespass law treated cause as fault.) Of course, if we are emphasizing his relative lack of moral or legal fault compared with a fault in the first instance driver (which is not the relevant comparison) we may say he is not "to blame" for the death. "Blame" has different meanings, and also is a comparative concept: "blame" in what sense and compared to whom is frequently the question. "No fault" driver who hits no child is not to "blame" (for death) in two senses: there is no causation of death, and no independently proved carelessness in the first instance. "No-fault" driver who hits a child is to "blame" in the causation sense but not the other sense. Thomson does not demonstrate that the two drivers are morally equivalent.

8. Thomson, supra note 1 , at 145 (emphasis in original).

9. Id. at 146 (emphasis in original). 
vest is at the cleaner on the day of the crime. Surely, Professor Thomson claims, the bad luck of the vest's absence will not "work in a court" 10 to free the defendant.

Aside from the erroneous assumption that law and morality must coincide, ${ }^{11}$ she misstates the moral sophisticate's view. The moral sophisticate holds that a man is not to be blamed for any consequence, period, whether or not luck entered into it in any way. A man is to be judged based on the goodness or badness of his original act, divorced of and regardless of its consequence, i.e., regardless of whether death is actually produced or not. In other words, the moral sophisticate's view-but not the legal view-is that the defendant is to be blamed equally, whether he has the good luck (vest on) and death doesn't result, or the bad luck (vest off) and death does result. It is the intention, the "setting of oneself," that is the significant determining factor of fault, and in both cases the intention is the same. The moral sophisticate would not argue that this defendant in the example cannot be found at fault. This defendant is blameworthy in the same degree as if the vest had been on. Blame for a death is something alien to the moral sophisticate's view, because consequences of an action are irrelevant. This is the real reason the moral sophisticate believes the bad outcome adds no increment of fault to the "fault" driver.

\section{An Explanation of Why Outcome Matters Practically-and Why It Matters in Almost All Cases}

\section{A. A REAL WORLD EXPLANATION}

I have just argued that what actually results from an actor's conduct should not matter morally. I have stated my belief that, when they rigorously examine their moral judgments, most people share this view. I have noted that Professor Thomson herself makes arguments that lead to this conclusion. Yet Professor Thomson maintains that, when faced with two equally careless actors, one who causes harm and one who does not, we do have a gut feeling that outcome should matter.

Professor Thomson relies on this gut feeling to assert that, at least in cases where there is fault in the first instance, outcome is morally relevant. I do not want to belittle a favorite tool of philosophers, namely the attempt to discover truth by personal intuition believed common to "all" or "most" people. At bottom, perhaps all philosophical arguments ultimately come to this. Intuition, however, is sometimes based on unexamined premises and associations. Reliance on intuition, therefore, can at times lead one astray. Such, I think, has happened to Professor Thomson. I believe that her intui-

10. Id.

11. The legal treatment of this example, and why it is different, is discussed infra in part II.B. 
tive reaction, that outcome matters morally, steers her wrong by masking a complex series of associations that she does not recognize. From a practical, "real world" perspective, she is indeed quite right. ${ }^{12}$ Outcome does matter. But it matters only in the practical sense, and in this practical sense it "matters" in many more instances than Professor Thomson's intuition leads her to believe.

Professor Thomson's article brings us into an artificial world where we can assume such things as exactly equal carelessness by two actors. However, we spend most of our time in the real world, where knowledge of exactly how careless an actor was is not available in the vast majority of cases. In the real world, the consequences of an act provide legitimate and valuable data that help us pass moral judgments through the light they shed on the degree of carelessness that the actor probably exhibited. More often than not, an act that produces a bad result is the product of careless conduct.

A vast number of acts or omissions are involved in even the simplest of real world situations. Thus, even when we have substantial result-independent evidence of an actor's conduct, outcome may still be an important clue in deducing how much care an actor most likely took. Consider again Professor Thomson's example of two careless drivers backing out of their driveways. One hits a child, while the other does not only because he is "lucky" and no child is present. Let us presume that eyewitnesses saw both drivers and can testify that neither driver turned around while backing out to look to see if a child was there.

Despite this eyewitness testimony, there are a multitude of steps one driver and not the other may have taken to attempt to avoid hitting a child. One driver may have glanced in the rearview mirror or looked around before getting into the car. One driver may have thought about whether any children lived near his house, while the other may not have. In short, there may have been a reason why the one "careless" driver hit a child and the other "careless" driver did not: the one who did not may have taken one of these steps, or demonstrated more care than the driver who hit a child in one of a myriad of other possible ways. In the absence of completely definitive proof (which is perhaps impossible to acquire) that each driver was equally careless, we are justifiably inclined to believe that the driver who hit the child did not use precisely the same degree of care as the other and therefore is more morally culpable. This judgment, though, should be provisional, subject to change if later received information warrants it. ${ }^{13}$

12. I reiterate that, in this section, I am accepting for the sake of argument only her assertion that "outcome matters." I am attempting, also for the sake of argument, to proffer a "real world" explanation for her intuitive conclusion.

13. The example I use here mentions differences between the two drivers in affirmative steps they may have taken. There may have been differences in circumstances which did or should have come 
Thus, outcome is important to consider in making real world moral judgments, not because it is a morally relevant factor in and of itself, but because it fairly well correlates with the extent of the actor's carelessness, which is a morally relevant factor and which we often are not able to establish completely with direct evidence. However, Professor Thomson's paper presents us with an artificial world in which we are allowed to assume exactly equal degrees of care by actors whose actions produce different results. If the above argument is correct, then, outcome should not be material in our moral consideration of Thomson's examples. Yet Thomson claims that we do intuitively feel that, even when we assume equal degrees of carelessness, outcome still matters.

I agree with Thomson: many people do intuitively feel this way. I disagree, however, with her interpretation of this observation. Professor Thomson takes the intuition at face value; I suggest that this is too quick an acceptance of an unanalyzed gut feeling, and that a more complex dynamic is involved.

As stated above, while not a morally relevant factor in itself, outcome is often a good guide to provisional moral judgments in the real world. Furthermore, bad outcomes are often the means by which careless acts come to our attention; we never know of the thousands of drivers who carelessly back down their driveways every day and don't hit children, but we all hear about the one who does hit a child. Finally, since we do not have the time and motivation to investigate the circumstances surrounding the causation of most bad outcomes we become aware of, our provisional moral judgments of condemnation become final. ${ }^{14}$

All of these factors, I believe, combine to create an intuitive association in our minds between bad outcomes and moral culpability. Unless we are somehow reminded of it, we forget that bad outcome is only linked to moral culpability through the careless conduct that bad outcome makes more probable.

Thus, while Professor Thomson's assumption of equal care breaks the logical link between bad outcome and moral culpability_by making outcome

to their attention, e.g., children did or didn't live in the neighborhood. The probability of these, too, is suggested by the result. My analysis in this article also works for "good" acts, "beneficial" outcomes, and those that are morally neutral; and for intentional, as well as merely negligent, wrongdoers.

It is the subject of another paper whether the "moral sophisticate's" position can recognize "inadvertent negligence," as opposed to "advertent negligence."

14. It should be pointed out that the common tendency to judge the one who produces the harm more harshly than the one who does not arises partially from an additional factor: It is difficult to say exactly what is the "right" degree of care in most situations, even if we knew exactly what steps of care were taken. This is because the "right" degree involves a balancing of benefits and burdens (including probabilities and risks), which is somewhat intangible. People tend to refer to actual outcome to help decide if there were unjustifiable risks. 
completely undeterminative of carelessness-it does not sever the intuitive, though invalid, association we have developed between the two. This accounts for the gut feeling that outcome matters which Professor Thomson notes.

Let us carry the analysis a bit further. Suppose that one of our careless drivers backing out of the driveway, the one who, in the last hypothetical, had hit the child, instead narrowly misses the child. This "near misser" would correspond to the hunter in Summers $v$. Tice ${ }^{15}$ whose bullet narrowly missed the plaintiff-whose bullet did not do the damage, although we didn't know in Summers which of the two hunters hit and which missed. Our thought would be that this "narrowly missing" driver must not have been keeping as careful a lookout as the other (the "widely missing") driver in our same example. ${ }^{16}$ Our thought that the near misser must have been less careful than the wide misser is rationally almost but not quite as strongly corroborated by this near miss as by an actual hit.

We place the probable degree of inattentiveness (and hence moral badness) of this near misser of the child just next to that ascribed to the driver who hits the child. But a driver who comes nowhere near a child has probably been more careful. This, I believe, explains in part the moral satisfaction we feel with the result in Summers $v$. Tice. In terms of the probability that they engaged in equally risky conduct, the two hunters (the one who hit the plaintiff and the one who nearly missed) are almost indistinguishable and were subject to the same terms of "punishment."17 Even if in Summers we had been able to find out which hunter actually harmed the plaintiff, this analysis explains why we might still equate them morally.

Again, Professor Thomson agrees with our assessment of the relative fault of the careless near misser vis-a-vis the careless wide misser and the careless hitter. She does not-and confesses she cannot-explain why. I submit she feels as she does because of the light a near miss sheds upon the care with which the initial act was probably executed.

15. 33 Cal. 2d 80, 199 P.2d 1 (1948).

16. We say he "widely misses" a child because no child was present.

17. Professor Thomson raises a question as to whether it would make any difference to how we would rank the near misser's fault in Summers vis-a-vis the hitter's fault (assuming we knew which was which) that the near misser's near miss was not a near miss of the same person hit by the hitter, but of another person, at another time and place. In other words, two people equally negligently shoot, at separate times and places, near separate "victims." One hits his victim. The other, accidentally, does not. Compare this hypothetical scenario with Summers (and assume in both we know who hit and who nearly missed). Are the hitter and the near misser in my hypothetical scenario equally at fault from a moral perspective? Or do the hit and near miss have to be of the same person (as they are in Summers) to be of the same degree? For Professor Thomson, this is a mystery. On my theory as outlined in this paper, the answer is clearly that it makes no difference whether it is the same victim or a different victim. The nearness of the miss, as demonstrating probability of bad conduct, is what counts. (We are talking morality here, not law.) 
The near miss situation is one (unexplained) exception that Professor Thomson sets out to her general rule that actual outcome matters. Professor Thomson also maintains that outcome does not matter where an actor is not at fault independent of result, or in my terminology not at fault in the first instance. However, a moment's reflection on my analysis of all the above examples and my rationale will show that it should make no difference whether the backing drivers (or hunters, or what have you) are supposed in the first instance to be "careless" (at fault) or not: taking out the word "careless" in the examples does not alter the disparity of fault we rationally feel exists among the driver who actually hits the child, the driver who nearly misses the child, and the driver who widely misses the child. ${ }^{18}$ Even the "careful" driver himself, who hits a child, will always feel he wasn't careful enough or as "faultless" as if he didn't hit a child. The "hit" is relevant to degree of fault even in cases of so-called "non-fault" in the first instance, though perhaps the hit is not alone sufficient to indicate serious enough fault for legal liability. The hit may not elevate his culpability into the high category or level occupied by the independently proved fault in the first instance drivers, but it does elevate it.

Professor Thomson seems to think that we assign no moral disapproval to actors not independently proved at fault in the first instance ("careful" actors), whether they cause harm or not. I think a fairer statement of the matter is this: We do disapprove more of the "careful" actor who causes harm than of the "careful" actor who does not, but it appears that we do not distinguish between the two cases; this appearance is based on the absence (generally) of legal liability in both cases. ${ }^{19}$ In the case of "careless" actors, one of whom causes harm and one of whom does not, the same appearance does not arise; the independent carelessness generally puts both actors in the range of legal liability, but the result determines whether anyone will get paid in tort and perhaps the degree of criminal penalty to be imposed.

I also dispute Professor Thomson's other example designed to prove that result only matters in cases of fault in the first instance. She sets out the example of the person who, by idly tapping his foot on the sidewalk, saves three lives through some freak of nature unknown to him. Professor Thom-

18. In fact, it begs the question to ascribe the phrase "fault" or "no-fault" to the drivers in the first instance, since the outcome is one of the pieces of data we use to determine the degree of care it is probable they used-i.e., one of the pieces of data we use to decide if they did something careless or "faulty."

19. The law does provide several instances where a so-called "careful" or "fault-free" act incurs liability if and only if harm results, providing support for my notion that result matters even in cases of so-called non-fault in the first instance. No-fault auto liability and strict liability are modern examples. Ancient trespass law is another example. These areas often start out as areas where bad result is felt to indicate probable fault in the first instance, further investigation being considered not worth the effort; or as areas where fault is considered irrelevant for social engineering reasons. Eventually the bad result itself may be considered fault. 
son says that our judgment of the morality of the foot tapping-neutral morality-is unaffected by the good result. I would say that people, particularly those saved, would feel very kindly disposed toward such a person, at least more so than toward a foot tapper who did not wind up saving anyone. (This is the relevant comparison.)

This might indeed be a mistaken reaction, and under Professor Thomson's hypothesized fact pattern, where the actor did not know he would save lives, it would be. However, in the real world, where pre-event knowledge and motivation are often unknowable, people would be perfectly correct to feel postively toward the life-saving foot tapper. This is because the analysis presented above for acts with negative consequences works just as well for acts with positive, or praiseworthy, consequences: that lives were saved by one foot tapper and not the other makes it slightly more probable that the first foot tapper took account of circumstances that might lead to life saving than that the second did.

\section{B. LEGAL ANALOGIES}

As outlined above, I believe that Professor Thomson's assertion that outcome is morally relevant, at least in a substantial number of cases, is the product of an intuitive association between two statistically related but distinct concepts, bad outcome and moral culpability. However, this should be taken to minimize neither the real world relationship between the two concepts nor the pragmatic and legitimate use we make of it in our real world moral judgments. Moreover, since fault in the first instance is often of legal as well as moral consequence, it should come as no surprise that we utilize the empirical correlation between outcome and fault in the first instance in making legal judgments as well.

For instance, the criminal law distinguishes among the following three kinds of acts: (1) mere preparatory steps toward the commission of a crime, which are generally not punishable at all unless they constitute crimes in their own right, and even then are generally punishable only at a low level; (2) steps that have progressed further, to the point where they almost succeed in perpetrating the relevant crime and thus constitute an "attempt," which is punishable at a higher level than preparatory steps but at a somewhat lesser level than successful completion of the crime attempted; (3) the actual accomplishment of the crime itself, usually punishable in a greater degree than the attempt.

These three types of acts show differing degrees of demonstrated probability of dangerousness and are correspondingly punishable at different levels. Take, for instance, the following three scenarios: (1) A gunman obtains a gun to kill someone but never comes across the intended victim. This is a mere preparatory step, perhaps punishable at a low level for unauthor- 
ized possession of a firearm. It would not bear as high a penalty as attempted murder. (2) A gunman pulls the trigger while aiming at someone, but the gun jams or the intended victim is wearing a bullet proof vest. This is attempted murder. (3) A gunman succeeds in killing the victim because the gun does not jam or the victim is not wearing a bullet proof vest. This is murder and bears the highest penalty of the three.

The amount of dangerousness we can be sure of is different in each scenario. We cannot be certain of the bad intention of the first gunman. Nor can we be sure that the second gunman did not consciously or unconsciously take account of the gun's disrepair or the victim's bullet proof vest. In other words, perhaps he can take credit for these "chance" circumstances in the world that are supposedly "outside his control," to use some of Professor Thomson's terminology to reverse effect. This gunman might not have pointed and attempted to fire a gun had there not been circumstances creating a good chance of escape for the "victim"-at least he has not demonstrated that he would. The third gunman has.

These three categories correspond roughly to the driver who does not come close to hitting a child, the driver who nearly hits a child, and the driver who hits a child, respectively. The results of each driver's actions bear on our moral judgments only to the extent of the light they shed on that driver's carelessness in the first instance. By the same token, whether our hypothetical gunman fits into category one, two, or three is relevant not because we think that a would-be killer who is apprehended before he gets a shot off is intrinsically less worthy of punishment than the gunman who escapes capture until he is able to kill his victim. Rather, the problem is that, in the real world, we are not certain that the former will actually become the latter. ${ }^{20}$

We justifiably differentiate morally, as well as legally, among these three gunmen. Professor Thomson agrees with my moral distinctions here but not with my reasons for making them. This case happens to be a case of fault in the first instance. The presence of fault in the first instance, however, is not essential. Common morality rightly attaches an increment of condemnation when there is a near (as opposed to a wide) miss and when there is a hit (as opposed to a near miss). Under my analysis set forth above, each incremental condemnation is explained and is proper where there is fault in the first instance and where there is not.

20. The "gunmen" criminal law examples also make clear that conduct that produces a "wide miss" (the crime of unauthorized possession of a firearm) is not necessarily totally blameless if on grounds other than its result or nearness thereto, it is clear that the conduct presented some risk. Because of her concentration on tort cases, where the compensation principle comes into play only when there is someone to compensate, it at times looks as though Prof. Thomson believes that the shooters, who do not hit or come close to hitting someone, have not committed a blameworthy act. 


\section{THE SINDELL CASE}

Changes in our modern society have in many circumstances removed the need-even in the legal arena-to use the result of a particular actor's conduct as a clue to the degree of risk probably presented by an actor's conduct. In today's world, in fact, the result of any particular actor's conduct is often unclear. In other words, more cases have become like Summers v. Tice, ${ }^{21}$ with a hit or hits and verifiable near misses that make the equal or near equal fault of the actors clear even independent of the results of particular actors' conduct, and also with complex facts that make it difficult to determine exactly who caused what. Sindell v. Abbott Laboratories ${ }^{22}$ embodies these characteristics. In Sindell, the plaintiff charged that her cancer was caused by the DES taken by her mother while the mother was carrying the plaintiff. The plaintiff also alleged that, at the time her mother ingested the drug, DES manufacturers knew or should have known that DES (of the common formula used by all manufacturers) could cause such cancers. She also alleged strict liability. However, the woman, understandably given the passage of time since her mother's use of DES, could not prove which manufacturer was responsible for the particular DES her mother took. Nevertheless, the plaintiff won the right to go to a jury against a group of defendants that included most of the principal manufacturers of DES.

Each time our now infamous drivers backed down their driveways, their act was a unique event. By contrast, the risk potential of the DES formula used in the product marketed by the defendants in Sindell had a track record and could be documented epidemiologically: in so many cases out of so many, it produced this injury. Therefore, we do not need to refer to whether a particular manufacturer's DES caused a particular cancer to know how risky the manufacturer's marketing DES of this formula was. In the case of the drivers, we are not so sure what risk each presented without reference to, among other things, the particular result each caused.

Thus, even if any given DES manufacturer did not cause the particular harm inflicted on the plaintiff in Sindell, that manufacturer's production of the drug could be seen as nearly causing the harm. Defendant $A$, by selling DES of a formula that produced many injuries of precisely the type plaintiff incurred from somebody's identical DES, "came very near" to being the causative agent, even if that manufacturer's DES did not happen to be the particular DES that injured plaintiff. This "corroborates" the risk presented by $A$ 's marketing of DES. Even if we were to discover which manufacturer's DES actually caused the plaintiff's injuries, there would be no reason to distinguish legally—or morally—between that manufacturer and another. By thus

21. 33 Cal. 2d 80, 199 P.2d 1 (1948).

22. 26 Cal. 3d 88, 163 Cal. Rptr. 132, 607 P.2d 924, cert. denied, 449 U.S. 912 (1980). 
demonstrating the irrelevance of the outcome of a particular actor's conduct when it is not needed to indicate the probable degree to which the actor was at fault or presented risk in the first instance, Sindell supports the real world justification for outcome I have put forth: outcome is not a moral consideration in its own right, but rather is valuable only as an empirical indicator of the degree to which the actor was at fault (or presented risk) in the first instance and thus was morally or legally culpable or responsible. ${ }^{23}$

When you know the nature of the act, you may object, why should there need to be any injury at all? If we know that all the DES manufacturers were identically risky or careless, they are all equally at fault and should all be equally penalized, regardless not only of which one actually caused a given harm, but also of whether any manufacturer caused any harm at all, or whether there were any actual near misses, or whether there are any injuries or near injuries from any source. ${ }^{24}$ Indeed, the criminal law in many instrances does just that. Violations of various industrial safety regulations incur penalties whether or not anyone is actually injured or whether there were any actual close calls.

But in tort law we usually only shift the loss from where nature has dealt it when there is a plaintiff and when, comparatively speaking, the defendant is more of a wrongdoer than plaintiff. That, in itself, is no explanation. In addition, however, tort law requires some kind of harm, probably for the pragmatic reason that courts, being a rationed resource, should be conserved for cases of real need. But it also requires some kind of connection between the wrong and the injury to the victim. Just why, and what the nature of that connection must be, is somewhat problematic. Probably it is because, in

23. Notice I say several times "was at fault or presented risk." The strict liability part of Sindell perhaps is saying that presenting a risk, which strict liability law says you should pay for, is "fault." But that does not (at least as yet) accord with common notions of fault, which take into account justifications, countervailing benefits, and knowledge (or negligence about knowing) at the time of the act. (Some day common morality may grow to embrace the developing strict liability case law). The strict liability part of Sindell probably merely translates our analysis of how we use result as a clue to fault in the first instance into an analysis of how we use result as a clue to risk presented, the important factor in strict liability cases.

Prof. Thomson misses the point that the erosion of cause in Sindell also applies to strict liability. She assumes Sindell is a negligence case. By so doing, she misses the real enormity of that decision. A significant portion of our community might agree to the erosion of the causal requirement where actors are otherwise at fault (as the two hunters were in Summers) but not where they are fault free. Perhaps partly for this reason, the decision in Sindell does not highlight that it applies to the strict liability count; and, in contrast to Summers' joint and several liability for the whole, reduces liability to accord with market share. There are other reasons for the reduction, too, e.g., decreased likelihood (as compared with Summers) that any individual defendant actually caused the damage, and economic reasons.

24. Of course, we might not know the conduct is risky (indeed, it may not be risky) if there are no injuries from it or from similar conduct. In fact, the conduct may not come to our attention at all. Also, since risk is proportional to market share, we may want to adjust the penalty according to risk created, i.e., according to market share. 
the general case, we need the connection to show that the conduct was risky. But that is not always so, as Sindell shows. Sindell indicates that actual causation of a particular plaintiff's injuries is not always, and should not always, be required. But why is any connection needed? Why, for example, is it not enough that defendant acted wrongly and that plaintiff was independently injured by forces having nothing to do with DES and defendant? ${ }^{25}$ For example, suppose she was injured by a falling safe, and neither she nor her mother ever took DES. ${ }^{26}$

The answers that suggest themselves hinge on considerations other than moral ones. Victims of wrongs by others have an incentive to seek redress, as well as knowledge of the relevant events, so it makes sense to rely on them to sue those who wronged them. It also would introduce immense administrative complications to allow injured parties to sue any alleged wrongdoers they wished.

There are additional difficulties with allowing independently injured parties to recover from an unrelated tortfeasor. In the context of cases like Sindell, although outcomes in particular cases cease to be relevant as indicators of prior conduct and risk presented, "aggregate" outcome is clearly still relevant for those purposes. It is the knowledge of the overall number of DES users whose offspring developed cancer as a result of their mothers' use of DES that allows us to determine the culpability of the defendant in Sindell. ${ }^{27}$ In addition, recovery by independently injured parties might make defendants' liabilities disproportionate to the risk they engendered, which may have undesirable economic consequences. Sindell handles a similar problem that occurs when there is a requirement that the injury be related to DES by making liability proportional to market share.

Similar points can be made with respect to a case easier to visualize than

25. While Prof. Thomson recognizes that "the plaintiff has to prove some connection between his loss and the defendant's faulty act," she again fails to proffer any reasons for the necessity of this connection. Thomson, supra note 1 , at 137.

26. The Second Circuit recently upheld Judge Weinstein's settlement plan in the Agent Orange litigation. The plan provided payments for all veterans who had suffered "nontraumatic death or disability" and had served in areas where Agent Orange was used, regardless of whether those diseases had been caused by Agent Orange. In re Agent Orange Product Liability Litigation, 818 F.2d 145, 151, 183-84 (2d Cir. 1987) (series of separate opinions with same title covering various issues in appeals of Agent Orange settlement). In support of its decision, the court focused on the difficulty of linking the maladies of any particular veteran with Agent Orange, as well as the lack of evidence that Agent Orange was harmful at all. Id. at 149-50, 183-84. This settlement is expected to herald a new trend in toxic tort cases where causation is problematic.

27. If an alleged tortfeasor did not at least nearly cause harm, i.e., if it did not verifiably engage in exactly the same conduct, such as marketing DES, which injured an ascertainable number of people, then there would be no aggregate outcome to help indicate the risk the alleged tortfeasor presented. Thus, as well as illustrating that outcome is not a moral factor in its own right, Sindell also provides an example of the extreme usefulness of outcome in some form as a guide to the probable fault in the first instance of the actors involved. 
Sindell. To revert to an example used by Professor Thomson, let us suppose it is proved that all truckers maintain their brakes in the same identical improper fashion-a fashion that can cause them to fail. Because of the bad brakes, a child who is exercising due care is nearly missed by one driver of such a truck, but is hit immediately thereafter by another, also because of the bad brakes, but no one can prove which trucker was which. This is like Summers. In my view, and that of Kant and the moral sophisticate, if the identical degree of carelessness is a given, both are equally at fault (and a case can be made that both should be equally liable, too.)

If Kant, the moral sophisticate, and I are to be consistent with ourselves to the effect that morally, result doesn't matter when you know the nature of the act, you may object, why should it make any difference if we can prove which trucker was which? Both should be equally morally blameworthy (and probably equally liable) anyway. (The same question could be asked about the hunters in Summers.) Indeed, why should the child (or the victim in Summers) have to be nearly missed by the other or any other? Why shouldn't all the truckers who did the same negligent thing be responsible for the injury? (Some would say this is Sindell.)28 Indeed, further, why need there be any injury at all? If we know they all were indentically careless, they are all equally at fault and should all be equally penalized. (This applies to all these cases, including the truckers, Sindell, and Summers).

If we could be certain all the truckers' conduct was identical on this score, ${ }^{29}$ there should be equal "penalty" for them all whether or not there is any injury at all. Indeed, the criminal law would probably treat the matter that way (thus supporting Kant, the "moral sophisticate," and myself, as opposed to Professor Thomson): these truckers have probably violated the brake maintenance statute in their jurisdiction, and, assuming we can prove that ${ }^{30}$ they will all be punished equally, regardless of result. ${ }^{31}$ (Those that hit someone are probably not guilty of any additional crime, if we assume that the carelessness was not of the extraordinarily high variety required for manslaughter or negligent or vehicular homicide.)

But the tort law, for extraneous reasons, requires a victim. The money goes

28. With the slight modification that in Sindell, the different market shares meant different degrees of risk were presented by the different defendants. Their damages bills were thus adjusted accordingly.

29. As we can in Sindell; or at least we can know their relative degree of risk creation, without reference to this particular result. All we need to know is the statistical results concerning injury from this formula of DES generally and the market share of each defendant.

Sindell may be distinguishable in this respect from the truckers' cases, since, depending on the facts, it may be difficult to determine fault or risk creation of a defendant trucker without reference to some particular untoward result.

30. Here we are assuming the dereliction of each can be clearly established independently of untoward result.

31. Assuming it comes to anyone's attention without a hit or a near miss. 
to a victim for purposes of compensating him. But why is it not enough in tort law that defendant acted wrongly, and plaintiff was independently injured? For example, in the trucker case just above, suppose defendant (who negligently maintained his brakes) proves he came nowhere near the child and proves it was another trucker that hit the child. Indeed, why is it required that the child received his injuries from a truck, or from a truck with bad or negligently maintained brakes at all, in order to get compensation from this trucker who has badly maintained his brakes, assuming we can prove it? For example, why shouldn't he have to compensate the child for falling on the playground? Why should it matter if a hunter in Summers or a defendant in Sindell can prove they were not the causative one? Why should it matter whether there was a wide miss or a near miss or even whether or not plaintiff came to grief through shooting or DES (as opposed to some totally unrelated means) ${ }^{32}$ as long as we prove defendants shot negligently or wrongfully put DES on the market?33 Why should it matter how many potential defendants, and thus what the percentage probability is that the causing culprit was this defendant? Why should it matter whether all or even a large portion of the possibly causative agents (defendants) are identified or sued? The answer to why these things are thought to matter lies not in morality, but in law, economics, and ideas of social engineering.

\section{CONCLUSION}

While I believe Professor Thomson has overlooked a number of important considerations, her paper nevertheless does an excellent job of focusing attention on a significant evolution of the concept of causation in the philosophic

32. It is not entirely unheard of for us to feel that it is fair to make someone pay for something totally unrelated to what he has done. Criminal fines are often used for such things as defraying the bill for other community welfare projects, the poor and the sick, or to fund general criminal injury compensation programs for those other than the victim, if any, of this crime. Crimes are often ordered to be "atoned" for by the offender doing community service projects to alleviate some unrelated problem of the community .

33. And as long as, perhaps, there is some proportionality between the risk taken and the damages payable to plaintiffs-"The punishment should fit the crime"-although perhaps this is only applicable where one considers in advance the price one will have to pay for doing an act and chooses to do it (as in, presumably, intentional action or advertent negligence, where the risk is considered, but not inadvertent negligence). The proportionality theory is that we should not disappoint defendant's expectations as to the cost of doing the act. This could also be used as an argument for not making the defendant pay a plaintiff whose injuries he has not caused or not caused through a risk that was a knowable or expectable consequence in advance. You would be making him liable on the basis of less favorable chances than he bargained for, and had he known that he should make allowances for the chances of this too, he might not have done the act. In other words, just as you should not disappoint defendant's expectations as to the price he may have to pay for doing the conduct if a known or expectable risk materializes, you should not disappoint his expectations as to what the chances are that he will have to pay at all. The argument has slightly less force, however, in this later context for reasons I do not explore here. 
and legal arenas. It does so in an absorbing, thought-provoking, and readable fashion. I believe she set out to stimulate others to put pen to paper, and I have done so. The reader can decide who is "right," if there is such a thing as "right" in this area. 
